\title{
Study the Correlation between Serum level of Interlukin 6 and Lactate Dehydrogenase in Myeloma Patients at Stage III with Serum Creatinine and Calcium Level
}

\author{
Shaymaa Obaid Abdullah ${ }^{1}$, Hussein Jasim Al-Harbi \\ ${ }^{1}$ Department of biology, College of Science for women, University of Babylon, Iraq, \\ ${ }^{2}$ Department of biology, College of Science, University of Babylon, Iraq
}

\begin{abstract}
Multiple myeloma (MM) still an incurable disease that require better recognition and more research. Many previous studies shown the interaction between myeloma cells and bone marrow stromal cells for the initiation and progression of multiple myeloma . Many chemokines and their receptors including interleukin-6 (IL-6) an play important roles in this interaction. The main purpose of this study is assess the serum level of IL-6 and Lactate dehydrogenase on stage-III of MM patients and healthy controls then Finding the correlation with creatinine and calcium levels. Serum level of IL-6 , Lactate Dehydrogenase , creatinine and calcium levels of (30) MM patients diagnosis at stage -III according to International staging System (ISS) were measurement. The results for these parameters compare with (30) age- and sex-matched healthy controls groups. The results were showed that the mean levels of IL-6, Lactate dehydrogenase , creatinine and calcium (increased or decreased)high significant $(\mathrm{p} \leq 0.001)$ when compared with healthy controls . The results of the study suggested the important role of chemokines including IL- 6 in the progression of the disease and its relationship with some biochemical parameters, especially in the stage-III of the disease.
\end{abstract}

Key Word : Multiple Myeloma, Interleukin 6, Lactate Dehydrogenase . stage III

\section{Introduction}

Myeloma or multiple myeloma (MM) are referred as a cancer of antibody producing cell (plasma cells) which derived from B-cells in the bone marrow ${ }^{1}$. it is a incurable malignant disorder characterized by a multifocal proliferation of clonal, long-lived plasma cells within the bone marrow (BM) and associated skeletal destruction, serum monoclonal gammopathy protien, immune suppression, in addition MM is a debilitating disease with features including hypercalcaemia, renal impairment, anemia and bone disease (summarized in the mnemonic $\mathrm{CRAB}$ )) causing a wide variety of complications leading to organ ${ }^{2}$ dysfunction and eventually death ${ }^{3}$.

IL-6 is a major pro inflammatory a soluble mediator cytokines with a pleiotropic effect on immune response , inflammation and hematopoiesis ${ }^{4}$. When it was detected functions of IL- 6 were studied and given several names based on their biological activity. For example, the name
B-cell stimulatory factor 2 (BSF-2) was based on the ability IL-6 to induce differentiation of activated B cells into plasma cell ( antibody ( $\mathrm{Ab}$ )-producing cells, the name hepatocyte-stimulating factor (HSF) on the effect of acute phase protein synthesis on hepatocytes, the name hybridoma growth factor (HGF) on the enhancement of growth of fusion cells between plasma cells and myeloma cells, or the name interferon (IFN)-b2 owing to its IFN antiviral activity ${ }^{5}$. in 1986 Hirano and his Colleagues successful in cloned of BSF-2 c DNA ${ }^{6}$, and, it was found that the molecules with different names studied by various research teams were in fact identical, resulting in the single name IL - 6 (Rossi et al , 2015). Human IL-6 is made up of 212 amino acids, including a 28-amino-acid signal peptide ${ }^{4}$. The research that dealt with in the biology of MM has shown new insights into the factors that control the growth and survival of myeloma cells. Among the growth factors, interleukin- 6 (IL-6) has an essential role where it is involvement in the development of normal plasma cells ${ }^{7}$. also it now 
is clear that IL-6 is a potent myeloma cell growth factor involved not only in vitro but also in vivo ${ }^{8}$. Because the essential role of IL-6, it could serve as a target for new therapeutic interventions. Neutralizing the effect of IL-6 may result in a regression of tumor progression ${ }^{9}$.

\section{Subjects and Method}

1-Patients \& Healthy : The study subjects comprised of $30 \mathrm{MM}$ patients( 17 male and 13 female) , age $($ mean $\pm \mathrm{SD})=62.34 \pm 5.68$ (ranging from 45 to 80 years) These patients were suffered from MM diagnosis at stage III according to ISS where the level of Beta2microglobulin $\geq 5.5 \mathrm{mg} / \mathrm{L}$, and were referred to the Hematology Consultation Clinic in each of the teaching hospitals at Baghdad governorate (medical city) , Babil governorate (Marjan city) . Those MM cases then have been diagnosed by a specialized haematologist . Diagnosis was based on bone marrow aspiration, biopsies reports and other diagnostic criteria included complete blood counts $(\mathrm{CBC})$, serum protein electrophoresis and renal function (urea and creatinine) .. The healthy group included 30 individual (15 male, 15 female) age (mean \pm S.D) $=(55.96 \pm 4.7)($ range 45 to 60$)$, not suffer from any disease, served as a control group and this group matched with patient group. All subjects in this study were taken consent before participation in this study.

2-Biomarkers analysis : Venous blood samples were drawn from patients and control subjects by using disposable syringes . (5) $\mathrm{ml}$ of blood was obtained from each subject, pushed slowly into disposable gel containing tubes, allowed to clot at room temperature for 15 minutes and then centrifuged at $3000 \mathrm{rpm}$ for approximately 10-15. minutes, after that sera was obtained and stored at $-20^{\circ} \mathrm{C}$ until used (Lipppi et al ,2007). Quantitative detection of IL-6 in serum was done according to the industrial company (Bioassay Technology Laboratory (China), that depended on the technique of the quantitative sandwich enzyme immunoassay (ELISA) and Blood chemistry (Lactate dehydrogenase, creatinine and calcium) was assayed in serum using a clinical chemistry analyzer (kit from Shanghai Fosun Long March Medicine and Science co., Ltd.)

\section{Statistical Analysis}

Analysis of data was made by using Statistical Package for Social Science (SPSS) system/ version 23 Results expressed as mean \pm Standard division S.D . The analysis of variance (ANOVA), the independent sample T- test, and correlate bivariate were used for this purpose.

\section{Results}

Demographic data and clinical characteristics of MM patients and healthy controls are summarized in Table 1. The mean serum level of IL-6 in stage-III MM patients was $123.57 \pm 17.22 \mathrm{ng} / \mathrm{L}$, where it was higher than the mean of controls, which is $58.8 \pm 294.61 \mathrm{ng} / \mathrm{L}$, A similar results was observed of biochemical parameters ( Lactate Dehydrogenase, Calcium, creatinine ) record significant rise in MM patients compared with healthy controls figure (1) B, C, D. The mean of all parameters that measured in current study in females patient was higher from male patients. The result of the correlation and linear regression of IL- 6 and LDH with calcium and Creatinine are follow: There were significant positive correlations $(\mathrm{p}<0.05)$ between IL-6 with calcium and creatinine level also there were positive correlation between LDH with calcium and creatinine Figure (2), (3) respectively.

Table (1): Demographic data and clinical characters of MM patients (stage III) and healthy controls . Mean \pm S.D.

\begin{tabular}{|l|l|l|}
\hline $\begin{array}{l}\text { Subjects } \\
\text { Variables }\end{array}$ & MM patients & Healthy controls \\
\hline Age & $62.34 \pm 5.68$ & $55.96 \pm 4.7$ \\
\hline Gender (male / female) & $(17 / 13)$ & $(15 / 15)$ \\
\hline
\end{tabular}


Cont... Table (1): Demographic data and clinical characters of MM patients (stage III) and healthy controls . Mean \pm S.D.

\begin{tabular}{|l|l|l|}
\hline RBC counts $(106 / \mathrm{ml})$ & $2.514 \pm 0.429$ & $5.68 \pm 8.34$ \\
\hline WBC counts $(103 / \mathrm{ml})$ & $3.10 \pm 0.439$ & $9.806 \pm 0.814$ \\
\hline Platelets count $(103 / \mathrm{ml})$ & $188.142 \pm 17.43$ & $248 \pm 35.09$ \\
\hline Hb levels $(\mathrm{g} / \mathrm{dl})$ & $9.214 \pm 0.508$ & $12.82 \pm 0.944$ \\
\hline ESR(mm/hour) & $87.32 \pm 9.67$ & $18.25 \pm 3.34$ \\
\hline Albumin $(\mathrm{g} / \mathrm{L})$ & $110.571 \pm 9.253$ & $69.33 \pm 2.768$ \\
\hline Total protein(g/L) & $27.671 \pm 3.055$ & $36.106 \pm 1.656$ \\
\hline Bence Jones protein in urine & $\begin{array}{l}(30) \text { positive } \\
(0) \text { negative }\end{array}$ & $22.56 \pm 11.3$ \\
\hline Beta 2 microglobulin (g/L) & $\begin{array}{l}(0) \text { positive } \\
(30) \text { Negative }\end{array}$ \\
\hline
\end{tabular}
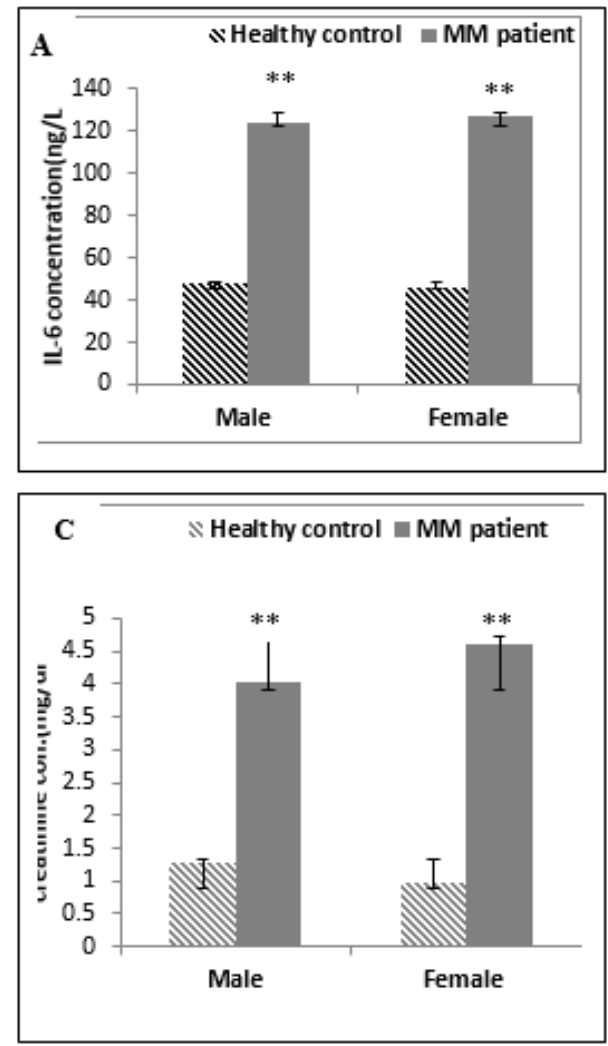
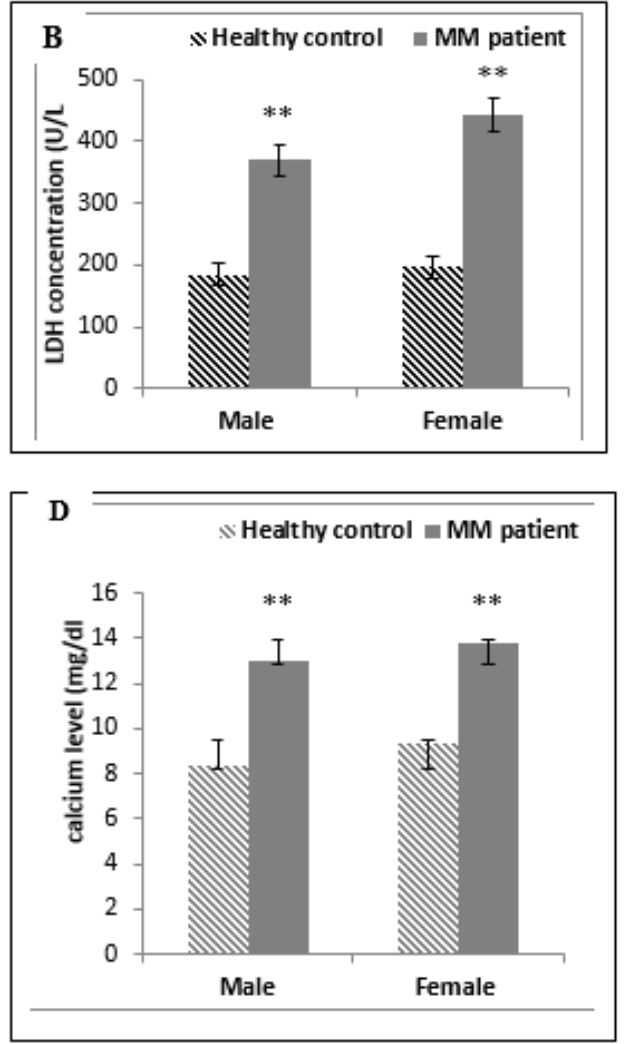

Figure 1. Comparison of the Mean Level of IL-6 (A), LDH (B), creatinine (C) and calcium (D) in the Population of Males and Females MM patients (stage III)and Healthy control. Results showed a significant difference in the mean level in both males and females $(* * \mathrm{P} \leq \mathbf{0 . 0 1})$ 

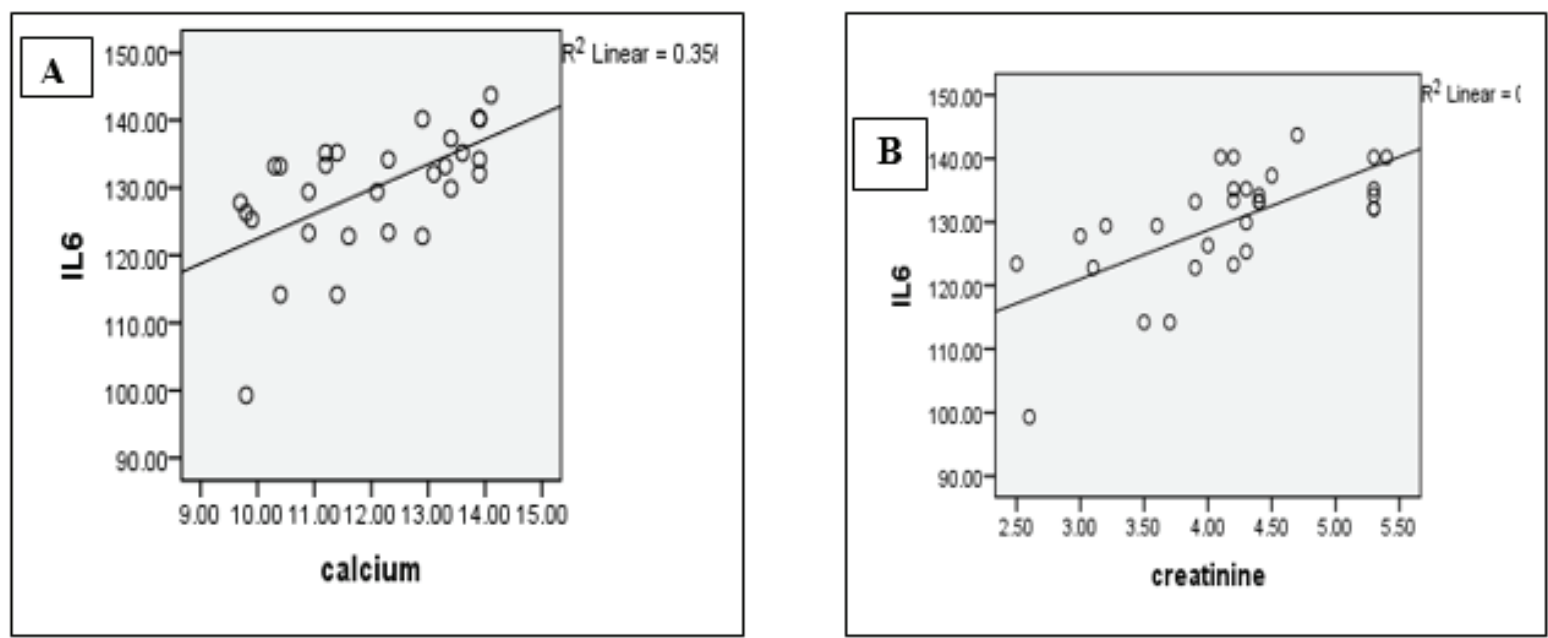

Figure 2. Correlation between IL-6 and calcium (A) and creatinine (B) in MM patients (stage III) . The results show positive significant correlation of IL-6 with calcium (Pearson's correlation $=0.70, P=0.004)$. and also with creatinine (Pearson's correlation $=\mathbf{0 . 8 2}, \mathrm{p}=\mathbf{0 . 0 0 1})$
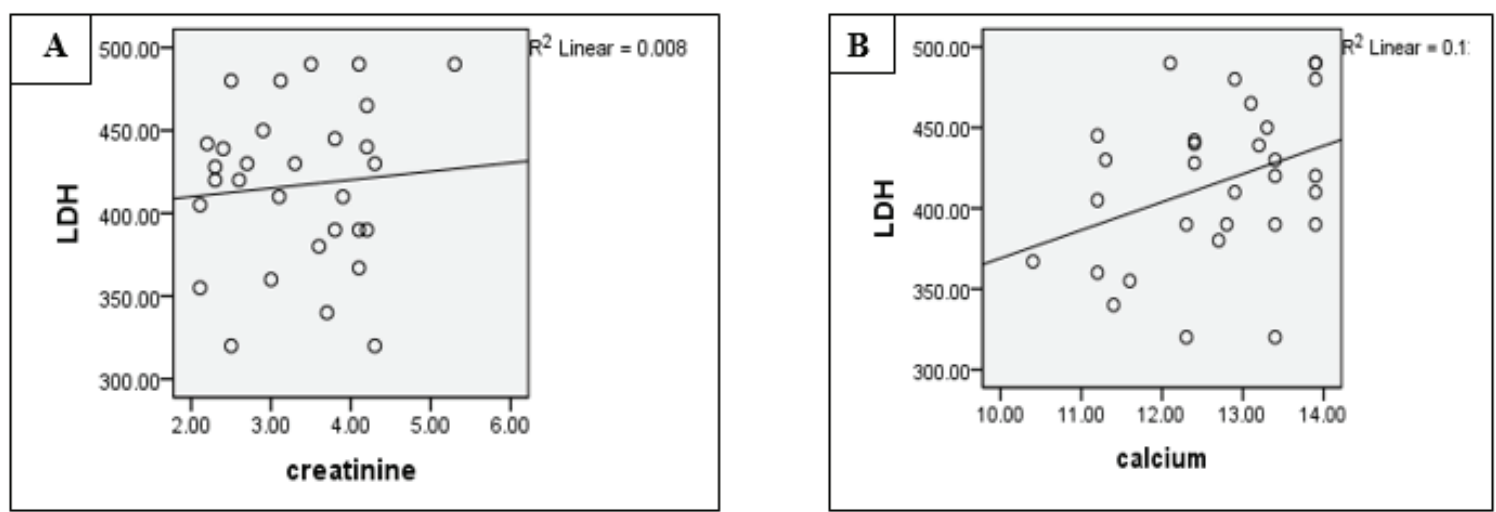

Figure 3. Correlation between LDH and creatinine (A) and calcium (B) in MM patients (stage III). The results show positive significant correlation of $\mathrm{LDH}$ with calcium (Pearson's correlation $=0.70, \mathrm{P}=\mathbf{0 . 0 1}$ ) and also with creatinine (Pearson's correlation $=\mathbf{0 . 5 8}, \mathrm{p}=\mathbf{0 . 0 4}$

\section{Discussion}

The pathogenesis of multiple myeloma was complex. The change of the level of cytokines took effect in its occurrence and development the disease ${ }^{20}$. Increased secretion of cytokine by bone marrow stroma often plays a main role in the pathogenesis of some of the clinical signs of multiple myeloma, such as bone disease and renal dysfunction. In our current study, a statistically significant higher level IL-6 was observed in the blood serum of myeloma patients at stage III according to ISS groups as compared to the healthy control group. Many studies have shown that serum levels of IL- 6 are elevated in patients with MM and correlate with the severity of the disease as ${ }^{11}$ other study as Bataille et al (2008) . showed that in patients with stage III MM, based on the Durie and Salmon classification, levels of IL-6 were significantly higher compared to patients with stage I and II disease. In addition, it was noted that elevated levels of IL-6 in serum was a good predictor of the severity of the disease . IL- 6 is a pleiotropic cytokine that was originally identified as a $\mathrm{T}$ cellderived lymphokine inducing final maturation of $\mathrm{B}$ cells into (plasma cell) antibody-producing cells ${ }^{18}$ also has been shown to regulate cell growth and It stimulates the growth of myeloma cells ${ }^{15}$. it has been reported that IL6-induced lymphoblastoid tumorigenicity due possibly to the inhibitory effect on tumor immunity of very high concentrations of this cytokine ${ }^{12}$. Therefore, it seems possible that IL-6 stimulates the growth of myeloma cells 
via autocrine and/or paracrine mechanisms and might contribute to tumor escape from immune surveillance, resulting in disease progression through the increased production of IL-6. Also patients with metastatic renal cell carcinoma have higher serum IL-6 levels than those without disseminated disease ${ }^{23}$. also, Alexandrakis et al. (2003) ${ }^{10}$ have reported that the levels of cell factors of MM patients such as serum IL-6 and angiogenine were increased significantly. And the increase degree was parallel to clinical staging and severity of diseases. It indicated that the level of IL- 6 was concerned with MM progression and the severity. Renal impairment (RI) and osteolytic is one of the most common complications of $\mathrm{MM}^{13}$ indicates a higher tumor burden and consequently more aggressive disease Heher (2013) . Also In our current work, we found a positive correlation between the level of IL- 6 with the level of creatinine and calcium while Singh et al , (2015) ${ }^{22}$ found elevated in IL-6 in MM patients also there is positive correlation between IL- 6 and creatinine level and no correlation between IL-6 with calcium. High levels of LDH are associated with advanced disease and poor survival where our results record significant increase in LDH level in stage III MM patient in addition the result of study Proven presence the positive correlation between LDH with creatinine and calcium level in MM patients. This indicates the progress of the disease where LDH is a cytoplasmic enzyme and may have been observed in nearly all major organ cells. If cells lysis occurs, or cells and membranes are damaged, cytoplasmic enzymes, such as LDH are released into the extracellular area. therefore serum LDH levels are as useful markers like beta-2microglobulin and monoclonal immunoglobulin. During the observation of the patients with MM at stage III, if the LDH levels are abnormally high, the progression of the disease should be considered .

Financial Disclosure: There is no financial disclosure.

Conflict of Interest: None to declare.

Ethical Clearance: All experimental protocols were approved and all experiments were carried out in accordance with approved guidelines.

\section{References}

1. Mohammed N, Murthy S, Dattatreya P. Serum free light chain ratio in correlation with serum protein electrophoresis in multiple myeloma patients from south india, Int J Pharm Bio Sci. 2015; 201: 1074 1080.

2. Ring E, Michelle A, Lawson A. New agents in the Treatment of Myeloma Bone Disease (review) . Calcif Tissue Int. 2018; 102:196-209 .

3. Fairfield H, Falank C, Avery L, Reagan M. Multiple myeloma in the marrow: pathogenesis and treatments , Ann N Y Acad Sci. Author manuscript; available in PMC. 2017; 1364(1): 32-51.

4. Tanaka T, Narazaki M, Kishimoto T. IL-6 in Inflammation, Immunity, and Disease. Cite this article as Cold Spring Harb Perspect Biol. 2014; 6:a016295.

5. Hilbert D, Kopf M, Mock B. The Journal of Experimental Medicine. 1995; 182: 243-248.

6. Hirano T, Yasukawa K, Harada H. Complementary DNA for a novel human interleukin (BSF-2) that induces B lymphocytes to produce immunoglobulin. Nature. 1986; 324: 73-76.

7. Gadou K, Domjau N. Role of Interlukin-6 in the pathogenesis of multiple myeloma . Cell Biology International. 2000; 24( 4 ): 195-209.

8. Terpos E, Ntanasis-Stathopoulos L. Myeloma bone disease: from biology findings to treatment approaches. Blood. 2019; 133(14) : 1534 -1539.

9. Burger R, Günther A, Klausz K. Due to interleukin-6 type cytokine redundancy only glycoprotein 130 receptor blockade efficiently inhibits myeloma growth , Haematologica. 2017; 102(2):381-390.

10. Alexandrakis M, Passam, F . Relationship between circulating serum soluble interleukin-6 receptor and the angiogenic cytokines basic fibroblast growth factor and vascular endothelial growth factor in multiple myeloma. Ann Hematol. 2003; 82: 19-23.

11. Chou $\mathrm{T}$.Multiple myeloma: recent progress in diagnosis and treatment. J Clin Exp Hematop. 2012; 52: 149-59.

12. Choy E, Rose-John S. Interleukin-6 as a multifunctional regulator: inflammation, immune response, and fibrosis . J Scleroderma Relat Disord. 2017; 2(Suppl 2): S1-S5 .

13. Dimopoulos M, Sonneveld P. International Myeloma Working Group Recommendations for the Diagnosis and Management of MyelomaRelated Renal Impairment . journal of clinical 

oncology , 34(13) : 1544-1567.

14. EC Rennke H. Kidney Disease and Multiple Myeloma, Clin J Am Soc Nephrol. 2017;7; 8(11).

15. Lauta V. A Review of the Cytokine Network in Multiple Myeloma Diagnostic, Prognostic, and Therapeutic Implications, CANCER. 2003; 97(10) : 2440-2452

16. Lippi G, Luca G, Martina S, Guidi GC. Preparation of a Quality Sample: Effect of Centrifugation Time on State Clinical Chemistry Testing, Labmedicin. 2007; 38(3): 172-176.

17. Long S, Guo-An Chen G. Levels of interleukin-16 in peripheral blood of 52 patients with multiple myeloma and its clinical significance; Int J Clin Exp Med. 2015;8 (12) :22520-22524 .

18. Nakashima J, Tachibana M, Horiguchi Y. Serum Interleukin 6 as a Prognostic Factor in Patients with Prostate Cancer . Clinical Cancer Research. 2000; 6: 2702-2706 .
19. Plante $M$, Rubin S, Wong G, Federici $M$. Interleukin-6 level in serum and ascites as a prognostic factor in patients with epithelial ovarian cancer. Cancer (Phila.). 1994; 73: 1882-1888.

20. Preston S, Alison M, Forbes S. The new stem cell biology: something for everyone. Mol Pathol. 2003; 56: 86-96 .

21. Rossi J, Lu Z. Interleukin-6 as a Therapeutic Target .(review), Clin Cancer Res. 2015; 21(6) :of1-0f10.

22. Singh U, Shevra C, Singh S, Singh N. Interleukin-6 and interleukin-4 levels in multiple myeloma and correlation of interleukin- 6 with $\beta 2$ microglobulin and serum creatinine, clinical cancer investigation journal . 2015; 2(4) :211-215.

23. Teke H, Başak M, Teke D, Kanbay, M. Serum Level of Lactate Dehydrogenase is a Useful Clinical Marker to Monitor Progressive Multiple Myeloma Diseases: A Case Report . Turk J Hematol. 2014; 31: 84-87. 